\title{
Sex, food and conflicts: nutrition dependent nuptial feeding and pre-mating struggles in scorpionflies
}

\author{
Leif Engqvist
}

Received: 26 May 2006 / Revised: 27 October 2006 / Accepted: 27 October 2006 / Published online: 29 November 2006

(C) Springer-Verlag 2006

\begin{abstract}
Female and male reproductive interests often differ. In species in which matings are accompanied by a transfer of resources valuable for both participants, such as nuptial prey gifts, conflicts may readily occur. Scorpionflies may use alternative mating tactics. One is to offer a prey item (dead arthropod) to females in exchange for mating. This prey gift tactic includes a conflict because a male must decide on whether to offer the gift rather than to fight the female and consume the gift. The outcome may depend on the nutritional status of both males and females. Males may be more willing to give if they themselves are satiated and the condition of the females may influence the payoff from the males' investment. Similarly, females may be more willing to accept food gifts if they are in poor nutritional condition. In this study of the scorpionfly Panorpa cognata, I experimentally manipulated the feeding history of both males and females. I observed the outcome of the direct interactions that followed when males that were holding prey were approached by females. I found that well-fed males offered the food gift sooner than males in poor nutritional condition that fed extensively on the food item before offering. Female condition had no significant influence on whether prey items were offered by males or accepted by females. I also found that well-fed males rarely searched
\end{abstract}

Communicated by D. Gwynne

L. Engqvist $(\bowtie)$

Department of Evolutionary Biology and Ecology,

University of Bonn,

An der Immenburg 1,

53121 Bonn, Germany

e-mail: lengqvist@evolution.uni-bonn.de for prey to pursue the prey gift tactic in courtship. Thus, the prey tactic does not seem to be the males' first option.

Keywords Alternative mating tactics · Nuptial gifts .

Life history trade-offs $\cdot$ Resource defence $\cdot$ Sexual conflict

\section{Introduction}

In many animal mating systems, there is a large discrepancy between male and female reproductive interests leading to conflicts operating before, during or after mating (for reviews see Stockley 1997; Chapman et al. 2003; Arnqvist and Rowe 2005). Males of many species may defend resources that are crucial for female reproduction to achieve matings (Thornhill and Alcock 1983). If also male survival and/or development is limited by the same resource, there will be a trade-off between male immediate reproduction and male growth and survival (see also Roff 1992; Stearns 1992). Thus, a conflict over resource utilization between males and females might occur and the outcome of these interactions is likely to depend on the life history of both males and females in terms of male resource availability. Conditions for this described situation may be given in species with nuptial food gifts. In for instance hangingflies (Mecoptera, Bittacidae) and dance flies (Diptera, Empididae) in which males provide prey nuptial gifts, it was established that males sometimes feed on the gift extensively before offering them to the female (Thornhill 1983; Cumming 1994). Nevertheless, the significance of this behaviour has never really been examined in any depth. The present study focuses on a conflict situation over food items preceding copulation in the scorpionfly Panorpa cognata (Ramb.) (Insecta: Mecoptera). 
The mating systems of scorpionflies (Mecoptera: Panorpa), have been extensively studied and are characterised by the adoption of different male mating tactics (Thornhill 1981; Byers and Thornhill 1983; Bockwinkel and Sauer 1994; Sauer et al. 1998; Engqvist and Sauer 2003b) and sexual conflict at mating (Thornhill 1980b; Thornhill and Sauer 1991). In general, male scorpionflies may use one of three different mating tactics: they may either offer females (1) a dead arthropod (hereafter prey), (2) a salivary secretion, which are consumed by the female during copulation or (3) they may attempt to mate with the female without nuptial food gifts (Thornhill 1981; Sauer et al. 1998). Matings in P. cognata, however, are always accompanied by nuptial food gifts (Engqvist and Sauer 2003b). Thus far, interactions preceding copulations involving salivary secretions as nuptial food gifts were fairly well-studied in this species (e.g. Engqvist and Sauer 2001, 2002a, 2002b), but not much is known about copulations involving prey gifts (but see Engqvist and Sauer 2003b). Panorpa scorpionflies are scavengers, feeding on arthropod carrion, which is a highly limited resource and fights over food items are intense (Thornhill 1980a, 1987; Bockwinkel and Sauer 1994; Sauer et al. 1998, 2003). Therefore, interactions between the sexes involving prey hold the potential for some intriguing conflict situations as both males and females use prey as food. Males and females can both to some extent be characterized as income breeders (cf. Jönsson 1997 for definitions) and their reproductive success strongly depends on food intake as adults (Engqvist and Sauer 2003b). Food availability strongly influences female ovary development and female lifetime reproductive success (Engqvist and Sauer 2003b). Food intake also influences a male's chance of survival but more important is the development of the salivary gland, which is strongly affected by male nutrition (Engqvist and Sauer 2001). As male mating success depends on the ability to secrete saliva (Engqvist and Sauer 2003b), food intake is an important proximate factor influencing male reproductive success in P. cognata (Engqvist and Sauer 2003b) and in other scorpionflies (Sauer et al. 1998). Thus, when given a choice, food deprived males with poorly developed salivary glands may need food themselves and be less willing to provide females with a food gift compared to well-fed males. Furthermore, because food gifts are costly for males, there is a potential benefit of male mate discrimination and preference for females of high quality (Gwynne 1981; Dewsbury 1982; Bonduriansky 2001) as has already been demonstrated for saliva secretion copulations in this species (Engqvist and Sauer 2001, 2002b). But, females in good nutritional condition may be less dependent on further food intake than food deprived females. The net female benefit of food gifts may thus depend on the female nutritional status and may even be negative for well-fed females if the females otherwise suffer some direct costs of mating (see e.g. Chapman et al. 2003; Arnqvist and Rowe 2005).

In line with these arguments, I therefore predicted that nutritional condition as a result of food availability may change the reproductive behaviour of both males and females, as was shown for the mating system of other resource dependent gift giving insect species (e.g. Gwynne 1981). I specifically hypothesized that (1) males in good nutritional condition will be more eager to offer the prey as nuptial gift and (2) males will more readily offer gifts to well-fed, highly fecund females, but (3) females in poor nutritional condition will be more eager to accept gifts than females in good condition.

\section{Materials and methods}

Breeding and adult conditions

Adult scorpionflies used in the experiment were either $\mathrm{F}_{1}$ or $\mathrm{F}_{2}$ offspring of animals collected near Freiburg i. Br. in south western Germany in May (sire generation of $F_{2}$ offspring) and August 2003 (parents of $F_{1}$ ). I used established standard breeding protocols for scorpionflies (Sauer 1970, 1977; Thornhill and Sauer 1992; Engqvist and Sauer 2003a). Larvae were reared in Petri dishes $(\varnothing 12 \mathrm{~cm})$ in groups of maximally 20 at $18^{\circ} \mathrm{C}$ on a $12 \mathrm{~h}$ light: $12 \mathrm{~h}$ dark photoperiod inducing diapause development (e.g. Sauer 1970). Petri dishes contained moist filter paper and were supplied with small cut segments of mealworm (Tenebrio molitor) ad lib. Once larvae had reached the third larval stage, they were transferred outdoors to soil-filled open bottom cylinders $(\varnothing 40 \mathrm{~cm}$, depth $1 \mathrm{~m})$ that were placed in the ground. Here, they were further fed on a diet consisting of small cut mealworms until they entered diapause.

On the day of emergence (beginning of May 2004), both females and males were randomly assigned to two different treatments affecting nutritional status. Thus, a $2 \times 2$ factorial design was used. From day one until the mating trial (day 15 or 16), they were either fed every third day (good nutritional condition) with a segment piece of a mealworm or every sixth day only (poor nutritional condition). These are well-established conditions to create two distinct classes of condition in this scorpionfly (Engqvist and Sauer 2001, 2003a). Nevertheless, at the beginning of the experiment I weighed a sub-sample from both treatments of the males and females that had emerged first to asses the effect of the treatment. I then plotted the frequency distribution of body weight against treatment for both males and females and decided to set up a weight limit where otherwise a small fraction of the distributions from the two treatments might overlap. This weight limit that had to be exceeded for individuals in good condition and fallen below for poor 
conditional animals was set at $49 \mathrm{mg}$ for females (mean \pm SD, good: $63.2 \pm 8.5 \mathrm{mg}$, poor: $41.0 \pm 5.5 \mathrm{mg}$ ) and $46 \mathrm{mg}$ for males (mean $\pm \mathrm{SD}$, good: $52.1 \pm 3.4 \mathrm{mg}$, poor: $40.9 \pm$ $3.3 \mathrm{mg}$ ). Only six females assigned to the poor nutritional condition gained too much weight and had to be discarded using this procedure. Before the trials, the animals were individually kept in small plastic tubes $(8 \times 3.5 \mathrm{~cm})$ containing moist filter paper and food.

\section{Mating trials}

Trials were only performed on the second and third day after feeding. For all trials, plastic observation boxes $(10 \times$ $10 \times 7 \mathrm{~cm}$ ) were used in which the bottom were covered with a thin layer of moist filter paper. Prey food items consisted of approximately a third of a mealworm. These had been cut and prepared the previous day so they were relatively dry (mean \pm SD weight: $15.1 \pm 5.9 \mathrm{mg}$ ). On the day of the trial, these prey items were weighed and fixed to the middle of the mating box using a fine needle that were pierced through the filter paper. Subsequently, males were individually weighed and were allowed to enter a box each. At the time a male found the prey and started feeding, the time was recorded and a female with appointed condition was allowed to enter the box.

The experimental female entered the box in the following manner: The top cover of the box in which a sole male was feeding was removed. The female was carefully placed on the inside of the cover, which was then replaced on top of the box. Hence, the female entered the box hanging upside down from the top cover a few centimetres above the feeding male. I recorded the time when the male was approached by the female. The femalemale interactions were now intensively observed. First, the females were usually antagonised by the males, which monopolised and fed on the prey, but later on the males frequently started courting the females offering the prey to feed on in exchange for copulation. Male fighting and courtship behaviour are easily separated. When fighting, a male stands with its abdomen pointing towards the opponent and raises its fore and hind wings. Often the male also steps backwards against the opponent and rapidly moves its abdomen sideways trying to hit and sweep away the opponent with its powerful genital segment. During fighting and protection of the prey item, the defender will always try to be located between the prey and the offender. In contrast, during male offering a male steps away slightly from the prey and starts displaying by vibrating, rhythmical abdominal movements (see e.g. Byers and Thornhill 1983; Engqvist and Sauer 2003b) These movements are always in the up and down direction-never sideways. Similarly, wings are not raised but moved in rhythm with the up and down movement of the abdomen - an identical behaviour can be observed during male courtship in the absence of prey that bring about copulations involving saliva secretions (see also Engqvist and Sauer 2003b). Thus, in addition to the termination of male feeding, the criteria for male behaviour to be classified as active prey offering involves the stepping aside from the prey item in combination with active courtship display.

After I released the females in the boxes containing prey holding males, I thus first measured the proportion of females that were attracted to the prey in the different treatments. Next, I measured the proportion of these interactions in which the males were dominant in the subsequent struggle over the prey. In case the males won the fight, I measured the probability in each treatment that a male would offer the prey as a nuptial gift during any stage of the interaction. Finally, I measured the likelihood that a female would accept the offered gift and copulate with the male. During the advancing stages of the experiment, the sample sizes of the tests on which the estimates are based are thus continuously decreasing because it is for instance only possible to measure the proportion of offered gifts if females are actually attracted to the male and the male is dominant in the fight. As the main measure of male eagerness to offer the prey, however, I measured the time between the female approach and the beginning of male courtship, which indicates male intention to offer the prey as nuptial gift.

\section{Statistical analysis}

Most analyses in this study are concerned with proportions. For this purpose, I used generalized linear models with binomially distributed error terms linked to a logit function (see e.g. Venables and Ripley 2002) including male and female nutritional condition as predictor variables. The main question of this study - male motivation to offer the prey item as a nuptial gift depending on its own and the female condition-relates to the time that elapsed between the female approach and the male offering. As not all males approached by the female initiated courtship, it was not possible to determine this time duration for all pairs. Nevertheless, it would be a profound mistake to discard these data from the analysis as they are probably nonrandomly distributed and entail important information relating to the hypothesis. A survival analysis (also called failure-time analysis) allowed me to enter these data as censored observations (see e.g. Fox 1993; Therneau and Grambsch 2000). Thus, these observations were rightcensored at the time of either the male or female departure.

Prey size and the time a male has already been feeding on the prey item is likely to strongly influence male motivation to offer it when subsequently approached by the female. It is for instance conceivable that a male that 
has already been feeding for a long time on the prey item before being approached by the female will be sooner ready to offer it as a nuptial gift compared to a male that just started feeding on it. I therefore used both initial prey size and the time a male had been feeding on the prey item before being approached by the female as covariates in the analysis.

Before the final analyses, I checked for significant interactions indicating non-homogeneity of effects over groups. Non-significant interactions were removed from the model before the final analysis. All analyses were performed using R 2.1.0 (Ihaka and Gentleman 1996).

\section{Results}

At an early stage of the experiment, I noticed that apparently fewer males in the good condition treatment searched for prey items. Instead they were engaged in pheromone emission, which usually precedes copulations using the salivary secretion tactic (see Engqvist and Sauer 2003b). I therefore assigned a larger proportion of the newly emerged adult males to the good condition treatment. In total, I used 166 males in the experiment, 70 males in poor nutritional condition and 96 males in good nutritional condition. The proportion (and absolute numbers) of males in all four treatment groups $(2 \times 2)$ interacting with the female, dominating the prey fight, initiating courtship and finally copulating are given in Table 1 .
As already was suspected by the initial observations, a significantly larger proportion of the males in poor nutritional condition searched for and ultimately fed on the prey item (poor condition: 0.77 (54/70), good condition: 0.39 (37/96), likelihood ratio test ( $G$-test): $\chi^{2}=21.6, d f=1$, $P<0.001)$. Feeding males in good nutritional condition were more likely to be approached by females but this effect was not statistically significant (cf. Table 1). Most males were dominant in struggles for prey-only 5 out of 76 males lost against the female in the struggle over the prey item (Table 1) and no difference between male treatments could be observed (Table 1). Similarly, most males initiated courtship at some time point during the female-male interaction at the prey item (on average $76 \%$, cf. Table 1). Males in good nutritional condition were more likely to initiate courtship but this difference was not statistically significant (Table 1). However, after controlling for male prey feeding duration and prey size, males in good nutritional condition initiated courtship significantly sooner than males in poor nutritional condition (Fig. 1 and Table 2), whereas female condition had no influence (Table 2). Males that had been feeding longer on the prey item before the interaction courted the female significantly sooner than males that had been feeding on the prey for a shorter time (Table 2). In addition to the effects of long-term food availability, this analysis thus also indicates that male immediate satiation influences male motivation to offer the food gift. An alternative explanation would be that extensive feeding reduces the value of the prey and males are more willing to offer a low rather than a high quality

Table 1 Outcome of the female-male interactions around prey food items

\begin{tabular}{|c|c|c|c|c|c|c|}
\hline $\begin{array}{l}\text { Male } \\
\text { condition }\end{array}$ & $\begin{array}{l}\text { Female } \\
\text { condition }\end{array}$ & $\begin{array}{l}\text { No. of pairs } \\
\text { tested }\end{array}$ & $\begin{array}{l}\text { Proportions of females } \\
\text { attracted to prey }\end{array}$ & $\begin{array}{l}\text { Proportions of } \\
\text { males dominant } \\
\text { in interactions } \\
\text { around prey }\end{array}$ & $\begin{array}{l}\text { Proportions of males } \\
\text { initiating courtship }\end{array}$ & $\begin{array}{l}\text { Proportion } \\
\text { copulating }\end{array}$ \\
\hline \multirow[t]{2}{*}{ Poor } & Poor & 28 & $0.79(22)$ & $0.95(21)$ & 0.67 (14) & 0.79 (11) \\
\hline & Good & 26 & $0.77(20)$ & $0.90(18)$ & $0.78(14)$ & 0.93 (13) \\
\hline Total & & 54 & $0.78(42)$ & $0.93(39)$ & $0.72(28)$ & $0.86(24)$ \\
\hline \multirow[t]{2}{*}{ Good } & Poor & 19 & 0.95 (18) & 0.89 (16) & 0.75 (12) & $0.50(6)$ \\
\hline & Good & 18 & 0.89 (16) & $1.00(16)$ & 0.88 (14) & $0.71(10)$ \\
\hline \multirow[t]{3}{*}{ Total } & & 37 & $0.92(34)$ & $0.94(32)$ & $0.81(26)$ & $0.62(16)$ \\
\hline & Poor total & 47 & $0.85(40)$ & $0.92(37)$ & $0.70(26)$ & $0.65(17)$ \\
\hline & Good total & 44 & $0.82(36)$ & $0.94(34)$ & $0.82(28)$ & $0.82(23)$ \\
\hline \multirow{2}{*}{$\begin{array}{l}\text { Male } \\
\text { condition }\end{array}$} & & $t$ & 1.72 & 0.22 & 0.96 & -1.96 \\
\hline & & $P$ & 0.09 & 0.82 & 0.33 & 0.05 \\
\hline \multirow{2}{*}{$\begin{array}{l}\text { Female } \\
\text { condition }\end{array}$} & & $t$ & -0.43 & 0.34 & 1.23 & 1.56 \\
\hline & & $P$ & 0.66 & 0.73 & 0.22 & 0.12 \\
\hline
\end{tabular}

Both proportions and absolute numbers (in parenthesis) are given.

The sign of the $t$-value will be positive if the estimated probability of a certain event is higher for individuals in good nutritional condition. See text for further details on the GLIM procedure. Note that the sample sizes for the tests of each interaction are constantly declining during proceeding stages of the experiment. For instance, the sample size of the test of the different probabilities that males are dominant in interactions around prey are based on the number of females that are really attracted to the prey and not on the total number of pairs tested (including females that were not attracted to the prey) and so on. 


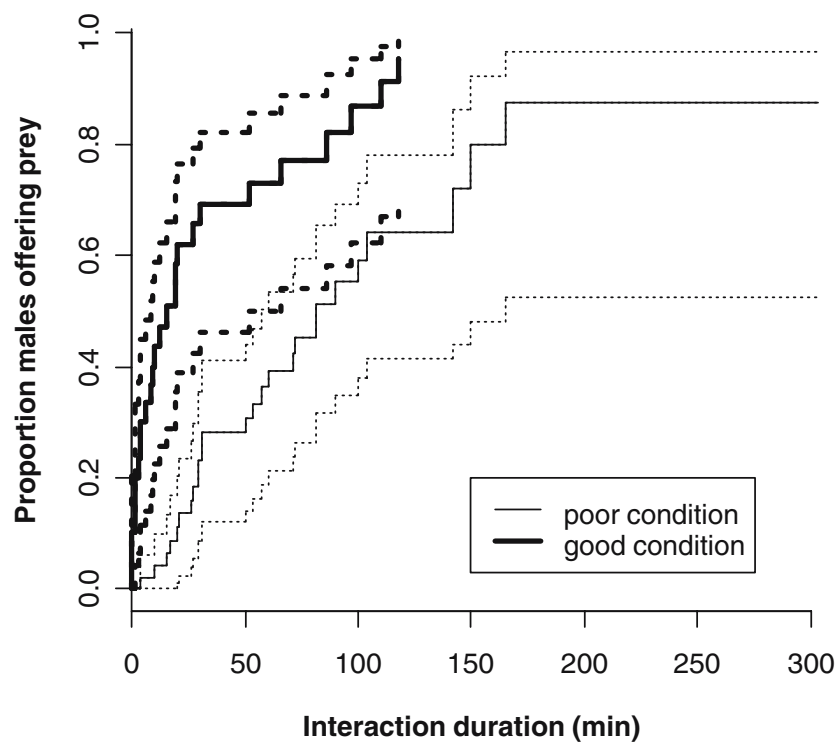

Fig. 1 Illustration showing the cumulative proportion of males offering females the prey as nuptial gift in relation to the time elapsed since the interaction started for well-nourished and poorly nourished males. Solid lines show the mean estimate, whereas dotted lines span the $95 \%$ CI. These estimates are based on the described Cox proportional hazards model taking into account the time a male had already been feeding on the item before the interaction started (see Table 2). From this illustration it can for instance be inferred that half the males in good condition had already initiated courtship by offering prey after ca. $15 \mathrm{~min}$, whereas the corresponding duration for males in poor condition was ca. $80 \mathrm{~min}$

gift. In contrast to this prediction, larger prey was on average offered sooner than smaller prey (Table 2). However, this effect was not statistically significant (Table 2).

Of the males that courted females, males in poor nutritional condition were significantly more likely to successfully achieve copulation (Table 1). This result may seem to contradict the previous result regarding courtship initiation. However, more females left males in poor nutritional condition as they were feeding and the fewer females that stayed for a long time until males in poor

Table 2 Summary of the survival analysis on the effects of male and female nutritional condition, male prior feeding and prey size on the interaction duration until courtship initiation using Cox proportional hazard

\begin{tabular}{llll}
\hline Predictor variables & $\beta \pm \mathrm{SE}$ & $t_{65}$ & $P$ \\
\hline Male condition (mg) & $1.24 \pm 0.31$ & 3.88 & $<0.001$ \\
Female condition (mg) & $0.06 \pm 0.29$ & 0.20 & 0.84 \\
Time feeding (h) & $0.60 \pm 0.27$ & 2.26 & 0.024 \\
Prey size (mg) & $0.045 \pm 0.026$ & 1.71 & 0.086 \\
\hline
\end{tabular}

The $\beta$-values give the regression coefficients for the estimated hazard function (likelihood ratio test $=18.2$ on $d f=4, P=0.001$ ). Positive values of $\beta$ indicate faster prey offering with higher values of the predictor variable. All first and higher order interactions were nonsignificant $(P>0.1)$ and removed before the final analysis. nutritional condition initiated courtship may represent a non-random sub-sample of females with a higher motivation to mate compared to the females staying with males in good nutritional condition until courtship (cf. also Engqvist and Sauer 2002a). Consequently, when comparing the proportion of interactions resulting in copulations, I found no significant difference between male treatments [good condition vs poor condition: 16 of $32(50 \%)$ vs 24 of 39 (61\%), $G$-test: $\left.\chi^{2}=0.95, d f=1, P=0.33\right]$.

In contrast to male nutritional condition, I found no significant effects of female condition, neither on the likelihood to approach males, win the fight, be courted by males, accept the food gift (Table 1), nor on the time until the male offered the gifts (Table 2).

\section{Discussion}

In this study I have investigated male and female behavioural interactions around food items, focusing on nuptial food offering preceding mating in the scorpionfly $P$. cognata. I found that males in poor nutritional condition were less eager to offer the food item as a nuptial gift compared with males in good condition. Instead, starved males first and foremost chose to feed themselves before offering the remaining food amount as nuptial gift (Fig. 1). In concordance, I also found that males that had been feeding for a long time on the prey item before the female approach were more willing to offer. I further predicted that female condition would both affect male willingness to offer and female readiness to accept gifts, but these hypotheses were not supported by the data (Table 1). In addition, I found that males in good nutritional condition were less active in search for arthropod food items.

The mating system of scorpionflies is a well-known example of resource defence polygyny (see Emlen and Oring 1977) selecting for alternative male mating tactics (Thornhill 1981; see also Thornhill and Alcock 1983). According to this traditional view, females are highly dependent on food resources for their reproduction. Males, which are dominant in contests for food, therefore exploit this resource dependence and monopolize the limited food resources to attain copulations with females. Inferior males, which are not successful in this intra-sexual competition for arthropod food items must make the best of a bad job and adopt alternative mating tactics (cf. also Gross 1996), such as relying on saliva secretions as nuptial gifts (which are supposedly less valuable and less preferred by females) or forced copulations (which are naturally averted by females) (Thornhill 1981). When more valuable resources become available, males adopting alternative tactics will switch and defend an arthropod food item instead (Thornhill 1981). This system as a general mating system for Panorpa 
scorpionflies has already been challenged by studies on $P$. vulgaris (Bockwinkel and Sauer 1994; Sauer et al. 1998) and previous work on P. cognata (Engqvist and Sauer 2003b) and the present study further strengthen alternative interpretations of the role of alternative nuptial gifts in the mating system of scorpionflies. First, not all males searched for food items in this study and primarily males in good nutritional condition refrained from doing so and instead emitted pheromones not attending an arthropod food gift. This behaviour can only result in a copulation involving a salivary secretion as nuptial gift but never in a copulation involving prey (cf. also Engqvist and Sauer 2003b). Second, similar to what was observed in previous studies (Engqvist and Sauer 2003b), once males did locate an arthropod food item, they did not focus on mate attraction but invariably fed on the prey item until a female found the way on its own. Finally, once a female was attracted to the male and the food item, males did not primarily attempt to initiate copulation, but first fed on the dead arthropod themselves. The time until eventual food offering did depend on the nutritional status of the male and the time the male had already been feeding preceding the female approach. These data do not at all accord with the established view of scorpionfly mating systems described above, but require alternative interpretations (see also Bockwinkel and Sauer 1994; Sauer et al. 1998; Engqvist and Sauer 2003b). The results obtained here do suggest that in $P$. cognata the decision on which mating tactic is used does depend on a conditional strategy (cf. Gross 1996). However, not the prey tactic but the saliva tactic seems to be the most preferred option by males and is adopted by well-nourished males (see also Bockwinkel and Sauer 1994; Sauer et al. 1998). Predominantly, poorly nourished males unable to or with low ability to secrete saliva, search and find food items. These are then possibly used in matings, but only after male own feeding.

Why is the saliva tactic preferred and why are dead arthropods primarily used as food resource for males and only secondarily as nuptial offerings? The answer must relate to the payoff for the different tactics and take into account the factual knowledge of scorpionfly reproductive behaviour. The saliva tactic yields considerably longer copulations than matings involving arthropod food gifts (Bockwinkel and Sauer 1994; Sauer et al. 1998; Engqvist and Sauer 2003b). Because the sperm is continuously transferred during copulation (Sauer et al. 1997; Engqvist and Sauer 2003a), these longer copulations will result in more sperm transferred and thus an advantage in the resulting sperm competition (cf. Sauer et al. 1998, 1999) in this mating system characterized by female multiple mating (Engqvist and Sauer 2003b). In addition, competition around food items is intense resulting in high frequency of disturbed matings at arthropod food items
(Bockwinkel and Sauer 1994). Strong intra-specific and inter-specific food competition (Thornhill 1980a, 1987) will probably also result in an advantage for males who immediately feed themselves in the first place instead of attempt to attract females using pheromones because competing males or individuals belonging to other more dominant scorpionfly species may also be attracted to the food item in the meantime. Further, as most males in the study fed extensively on the food item even when females were present, I propose that it is more advantageous for males to utilize the energy content of the food items in future saliva production than to use it immediately as nuptial food gift. Thus, easily eatable food items, which would result in short copulations, may be converted to less digestible saliva resulting in longer and thus more profitable copulations (see also Engqvist and Sauer 2003b). This interpretation is supported by the main result of this study: Well-nourished males with well-developed salivary glands (Engqvist and Sauer 2001) offer gifts sooner than poorly nourished males.

In a previous study on the influence of nutrition on mating behaviour in P. cognata (Engqvist and Sauer 2003b), I also found that salivary secretion is mainly a mating tactic used by males in good nutritional condition. However, in this previous study males in good condition were also more often involved in prey tactic copulations. The reason for this was twofold. First, males in good nutritional condition were more often involved in interactions around food items and second, interactions with males in good nutritional condition more often resulted in copulation (Engqvist and Sauer 2003b). The last results were not re-confirmed in the present study, on the contrary males in poor nutritional condition were more often present at food items and male condition did not significantly affect whether interactions resulted in copulations or not. However, the conclusions from the two studies do not necessarily have to be inconsistent. In the first study, male condition indices were based on lifetime data and not on current body weight as in the present study. However, to reach high body condition, males have to locate and feed on many food items and thus in a lifetime perspective, males in good condition may be able to use the prey tactic more often than males in poor condition (Engqvist and Sauer 2003b), although males presently in good nutritional condition search less intensely for food items as shown by the present study. Moreover, the previous finding that interactions around prey involving males in good nutritional condition are more likely to result in copulation (Engqvist and Sauer 2003b) could not be re-affirmed here. However, in the previous study, food items consisted of a one-segment piece of mealworm and were thus considerably smaller than in the present study. The rationale for using large food items, consisting of one third of a 
mealworm, in the present study was to avoid total consumption of the food items before interactions because the outcome of interactions around empty food items would be insignificant and non-interpretable. In the present study, I found that males in poor nutritional condition fed extensively on the food item before nuptial offering (Fig. 1). Thus, in the previous study, males in poor nutritional condition may often have completely exploited the small food item themselves and have had nothing left to offer females.

Female scorpionflies are highly dependent on food intake for reproduction (Thornhill 1980a, 1981, 1987; Sauer et al. 1998; Engqvist and Sauer 2001, 2003b). Nuptial food gifts may thus represent paternal investment, which may select for male mate choice (see review in Bonduriansky 2001), which taken to the extreme may result in complete sex role reversal (Gwynne 1981; Simmons 1992). It is conceivable that changing resource abundance will change the relative cost and benefit of nuptial food gifts for males and females, respectively. Thus, sex roles and reproductive behaviour in species with nuptial feeding may strongly depend on food resource abundance (Gwynne 1981; Gwynne and Simmons 1990; Simmons 1992). In this study, I found that higher food availability increased male incentive to provide food gifts and hence the intensity and duration of conflicts around food items decreased. However, in contrast to predictions, females in poor nutritional condition were neither more likely to be attracted to food items nor more likely to accept food gifts. Possibly, the slope describing female reproductive output as a function of additional food intake do not decrease considerably with increasing female condition. In this case, the selective pressure on females to find and consume dead arthropods will be equally strong irrespective of individual condition. Neither could I, during these interactions, find any evidence of male choice, which is a major feature of copulations involving salivary secretions in this species, especially for males in poor nutritional condition (Engqvist and Sauer 2001, 2002b). Courtship was somewhat more often initiated in interactions with females in better condition, but not significantly so $(82.3 \%$ vs $70.3 \%, P=0.22$, cf. Table 1 ) and there was no indication that courtship was initiated sooner in relation to female nutritional status (Table 2). I therefore conclude that male discriminatory behaviour against females of different quality is unlikely to be substantial in male-female interactions around food items preceding male nuptial gift offering in $P$. cognata. But, strategic behaviour with respect to the males' own condition is a major aspect to consider in this context.

Acknowledgements I thank Klaus Peter Sauer, Tim Schmoll, Jo Frommen and three anonymous referees for the valuable comments on the manuscript, the Deutsche Forschungsgemeinschaft for the financial support [LE 469/1-1] and Julia Leven, Christiane Fritsche and Kim Schmidt for the laboratory help. The experiments in this study comply with the current laws on animal use in Germany.

\section{References}

Arnqvist G, Rowe L (2005) Sexual conflict. Princeton University Press, Princeton

Bockwinkel G, Sauer KP (1994) Resource dependence of male mating tactics in the scorpionfly, Panorpa vulgaris (Mecoptera, Panorpidae). Anim Behav 47:203-209

Bonduriansky R (2001) The evolution of male mate choice in insects: a synthesis of ideas and evidence. Biol Rev 76:305-339

Byers GW, Thornhill R (1983) Biology of the Mecoptera. Annu Rev Entomol 28:203-228

Chapman T, Arnqvist G, Bangham J, Rowe L (2003) Sexual conflict. Trends Ecol Evol 18:41-47

Cumming JM (1994) Sexual selection and the evolution of dance fly mating systems (Diptera: Empididae; Empidinae). Can Entomol 126:907-920

Dewsbury DA (1982) Ejaculate cost and male choice. Am Nat 119:601-610

Emlen ST, Oring LW (1977) Ecology, sexual selection, and the evolution of mating systems. Science 197:215-223

Engqvist L, Sauer KP (2001) Strategic male mating effort and cryptic male choice in a scorpionfly. Proc R Soc Lond B 268:729-735

Engqvist L, Sauer KP (2002a) Amorous scorpionflies: causes and consequences of the long pairing prelude of Panorpa cognata. Anim Behav 63:667-675

Engqvist L, Sauer KP (2002b) A life-history perspective on strategic mating effort in male scorpionflies. Behav Ecol 13:632-636

Engqvist L, Sauer KP (2003a) Determinants of sperm transfer in the scorpionfly Panorpa cognata: male variation, female condition and copulation duration. J Evol Biol 16:1196-1204

Engqvist L, Sauer KP (2003b) Influence of nutrition on courtship and mating in the scorpionfly Panorpa cognata (Mecoptera, Insecta). Ethology 109:911-928

Fox GA (1993) Failure-time analysis: Emergence, flowering, survivorship, and other waiting times. In: Scheiner SM, Gurevitch J (eds) Design and analysis of ecological experiments. Oxford University Press, Oxford, pp 253-289

Gross MR (1996) Alternative reproductive strategies and tactics: diversity within sexes. Trends Ecol Evol 11:92-98

Gwynne DT (1981) Sexual difference theory: mormon crickets show role reversal in mate choice. Science 213:779-780

Gwynne DT, Simmons LW (1990) Experimental reversal of courtship roles in an insect. Nature 346:172-174

Ihaka R, Gentleman R (1996) R: A language for data analysis and graphics. J Comput Graph Stat 5:299-314

Jönsson KI (1997) Capital and income breeding as alternative tactics of resource use in reproduction. Oikos 78:57-66

Roff DA (1992) The evolution of life histories: theory and analysis, 1st edn. Chapman and Hall, New York

Sauer KP (1970) Zur Monotopbindung einheimischer Arten der Gattung Panorpa (Mecoptera) nach Untersuchungen im Freiland und im Laboratorium. Zool Jahrb Syst 97:201-284

Sauer KP (1977) The adaptive significance of genetic variability of photoperiodic response in Panorpa vulgaris. Zool Jahrb Syst 104:489-538

Sauer KP, Sindern J, Kall N (1997) Nutritional status of males and sperm transfer in the scorpionfly Panorpa vulgaris (Mecoptera: Panorpidae). Entomol Gen 21:189-204

Sauer KP, Lubjuhn T, Sindern J, Kullmann H, Kurtz J, Epplen C, Epplen JT (1998) Mating system and sexual selection in the scorpionfly Panorpa vulgaris (Mecoptera: Panorpidae). Naturwissenschaften 85:219-228

Sauer KP, Epplen C, Over I, Lubjuhn T, Schmidt A, Gerken T, Epplen JT (1999) Molecular genetic analysis of remating frequencies and 
sperm competition in the scorpionfly Panorpa vulgaris (Imhoff and Labram). Behaviour 136:1107-1121

Sauer KP, Vermeulen A, Aumann N (2003) Temperature-dependent competition hierarchy: a mechanism stabilizing the phenological strategy in the scorpionfly Panorpa communis L. J Zool Syst Evol Res 41:109-117

Simmons LW (1992) Quantification of role reversal in relative parental investment in a bush cricket. Nature 358:61-63

Stearns SC (1992) The evolution of life histories. Oxford University Press, Oxford

Stockley P (1997) Sexual conflict resulting from adaptations to sperm competition. Trends Ecol Evol 12:154-159

Therneau TM, Grambsch PM (2000) Modeling survival data: extending the Cox model, 3rd edn. Springer, Berlin Heidelberg New York

Thornhill R (1980a) Competition and coexistence among Panorpa scorpionflies (Mecoptera: Panorpidae). Ecol Monogr 50:179-197

Thornhill R (1980b) Rape in Panorpa scorpionflies and a general rape hypothesis. Anim Behav 28:52-59
Thornhill R (1981) Panorpa (Mecoptera: Panorpidae) scorpionflies: systems for understanding resource-defense polygyny and alternative male reproductive efforts. Ann Rev Ecolog Syst 12:355386

Thornhill R (1983) Cryptic female choice and its implications in the scorpionfly Harpobittacus nigriceps. Am Nat 122:765-788

Thornhill R (1987) The relative importance of intra- and interspecific competition in scorpionfly mating systems. Am Nat 130:711729

Thornhill R, Alcock J (1983) The evolution of insect mating systems. Harvard University Press, Cambridge, Massachusetts

Thornhill R, Sauer KP (1991) The notal organ of the scorpionfly (Panorpa vulgaris): an adaptation to coerce mating duration. Behav Ecol 2:156-164

Thornhill R, Sauer KP (1992) Genetic sire effects on the fighting ability of sons and daughters and mating success of sons in a scorpionfly. Anim Behav 43:255-264

Venables WN, Ripley BD (2002) Modern applied statistics with S, 4th edn. Springer, Berlin Heidelberg New York 